\title{
Development and validation of a predictive risk factor model for epidural re-siting in women undergoing labour epidural analgesia: a retrospective cohort study
}

\author{
John Song En Lee ${ }^{1}$, Rehena Sultana ${ }^{2}$, Nian Lin Reena Han ${ }^{3}$, Alex Tiong Heng Sia ${ }^{1,4}$ and Ban Leong Sng ${ }^{1,4^{*}}$ (D)
}

\begin{abstract}
Background: Epidural catheter re-siting in parturients receiving labour epidural analgesia is distressing to the parturient and places them at increased complications from a repeat procedure. The aim of this study was to develop and validate a clinical risk factor model to predict the incidence of epidural catheter re-siting in labour analgesia.
\end{abstract}

Methods: The data from parturients that received labour epidural analgesia in our centre during 2014-2015 was used to develop a predictive model for epidural catheter re-siting during labour analgesia. Multivariate logistic regression analysis was used to identify factors that were predictive of epidural catheter re-siting. The forward, backward and stepwise variable selection methods were applied to build a predictive model, which was internally validated. The final multivariate model was externally validated with the data collected from 10,170 parturients during 2012-2013 in our centre.

Results: Ninety-three (0.88\%) parturients in 2014-2015 required re-siting of their epidural catheter. The training data set included 7439 paturients in 2014-2015. A higher incidence of breakthrough pain $(O R=4.42)$, increasing age $(O R=1.07)$, an increased pain score post-epidural catheter insertion $(O R=1.35)$ and problems such as inability to obtain cerebrospinal fluid in combined spinal epidural technique $(\mathrm{OR}=2.06)$ and venous puncture $(O R=1.70)$ were found to be significantly predictive of epidural catheter re-siting, while spontaneous onset of labour $(\mathrm{OR}=0.31$ ) was found to be protective. The predictive model was validated internally on a further 3189 paturients from the data of 2014-2015 and externally on 10,170 paturients from the data of 2012-2013. Predictive accuracy of the model based on C-statistic were $0.89(0.86,0.93)$ and $0.92(0.88,0.97)$ for training and internal validation data respectively. Similarly, predictive accuracy in terms of C-statistic was $0.89(0.86,0.92)$ based on 2012-2013 data.

Conclusion: Our predictive model of epidural re-siting in parturients receiving labour epidural analgesia could provide timely identification of high-risk paturients required epidural re-siting.

Keywords: Epidural, Labour, Re-siting, Predictive model

\footnotetext{
* Correspondence: sng.ban.leong@singhealth.com.sg

'Department of Women's Anaesthesia, KK Women's and Children's Hospital,

100 Bukit Timah Road, Singapore 229899, Singapore

${ }^{4}$ Anaesthesiology and Perioperative Sciences Academic Clinical Program,

Duke-NUS Medical School, 8 College Road, Singapore, Singapore

Full list of author information is available at the end of the article
}

(c) The Author(s). 2018 Open Access This article is distributed under the terms of the Creative Commons Attribution 4.0 International License (http://creativecommons.org/licenses/by/4.0/), which permits unrestricted use, distribution, and reproduction in any medium, provided you give appropriate credit to the original author(s) and the source, provide a link to the Creative Commons license, and indicate if changes were made. The Creative Commons Public Domain Dedication waiver (http://creativecommons.org/publicdomain/zero/1.0/) applies to the data made available in this article, unless otherwise stated. 


\section{Background}

Inadequate relief of labour pain can be distressing to the parturient. Current pain relief modalities could include epidural analgesia, nitrous oxide (Entonox), intramuscular pethidine and intravenous remifentanil [1, 2]. Epidural analgesia is the gold standard for labour pain relief as it provides superior pain relief with minimal neonatal adverse effects [3]. However, a poorly functioning epidural catheter that does not provide adequate pain relief may require a repeat invasive procedure for re-siting. This would lead to further distress to the parturient and may place them at additional risk for complications from another epidural catheter placement [4].

Patient, obstetric and anaesthetic factors have been associated with inadequate pain relief with labour epidural analgesia [5-8]. In a retrospective cohort study conducted in our centre from 2012 to 2013, the incidence of epidural catheter re-siting in parturients with epidural labour analgesia was found to be $0.85 \%$ [4]. We identified independent association factors that were associated with epidural catheter re-siting, which included a greater quantity of dinoprostone (Prostin E2) used for induction of labour, a longer time taken to perform the neuraxial blockade, a higher incidence of breakthrough pain, requirement for Caesarean section for delivery and complications associated with epidural analgesia such as venous puncture as well as hypotension and shivering [4]. The area under curve (AUC) of the receiver operating characteristic (ROC) curve for this multivariate model was 0.894 .

Although active management such as epidural supplementation could increase the success rate of epidural analgesia, the timely recognition of the modifiable predictive risk factors of epidural catheter re-siting could allow targeted management, thereby potentially reducing the incidence of epidural catheter re-siting. Thus, the objective of this study was to identify predictive factors for epidural catheter re-siting, evaluate the predictive accuracy of these set of predictors (including demographic and clinical variables), as well as to validate them internally and externally for predicting the risk of epidural catheter re-siting. The latest 2014-2015 data was used to develop a predictive model, which was subsequently externally validated with the pre-existing 2012-2013 data from our previous study.

\section{Methods}

This is a retrospective cohort study that involved the collection of data of all parturients that received neuraxial analgesia (combined spinal epidural (CSE) or epidural analgesia) in KK Women's and Children's Hospital (KKH), Singapore, between January 2012 and December 2015. We included all women who underwent labour epidural analgesia at $\mathrm{KKH}$ and there was no specific sampling, inclusion and exclusion criteria as the database included all women. This study received approval by the Singhealth Centralized Institutional Review Board (CIRB) (Ref: 2017/2023 (2014-2015 data) and 2012/259/D (2012-2013 data)).

Our centre maintains an electronic database of details of labour neuraxial analgesia received by parturients, which is collated from the labour neuraxial analgesia forms. The electronic records of 10,628 parturients that received labour neuraxial analgesia from January 2014 to December 2015 and 10,170 paturients from January 2012 to December 2013 were obtained from the electronic database. Missing and outlier values were identified and the corresponding forms had values cross-checked and amended as appropriately.

\section{Labour neuraxial analgesia regime}

The type of labour neuraxial analgesia performed (CSE or plain epidural analgesia) and the local anaesthetic regimens used for labour analgesia was at the discretion of the attending anaesthesiologist on duty. For the induction of labour analgesia, a typical regimen of $2 \mathrm{mg}$ ropivacaine and $15 \mathrm{mcg}$ fentanyl was commonly administered intrathecally for a CSE and $10-20 \mathrm{ml}$ of ropivcaine $0.2 \%$ for plain epidural analgesia. For the maintenance of labour analgesia, a basal infusion rate of 5 to $12 \mathrm{ml} / \mathrm{hr}$. of local anaesthetic 0.1 to $0.125 \%$ ropivacaine or bupivacaine with fentanyl $2 \mathrm{mcg} / \mathrm{ml}$ was commonly used, with a bolus of 5 $\mathrm{ml}$ for each successful patient initiated demand.

\section{Data collection}

Maternal demographic data, including age, race, weight $(\mathrm{kg})$ and height $(\mathrm{cm})$ was recorded. Obstetric data collected included parity, use of dinoprostone (Prostin E2) for induction of labour, cervical dilatation and use of oxytocin for labour augmentation pre-neuraxial blockade, duration of second stage of labour as well as mode of delivery.

Anaesthetic data included the American Society of Anaesthesiologists physical classification status, use of intramuscular pethidine or nitrous oxide (Entonox) for analgesia pre-neuraxial blockade as well as pre- and post-procedure pain scores (measured on a Visual Analogue Scale of 0-10) [9]. The seniority of the attending anaesthesiologist (Specialist or Resident/Medical Officer), type of analgesia (CSE or plain epidural analgesia), type and concentration of local anaesthetic used for induction and maintenance of labour analgesia, level of insertion, number of attempts, time taken, number of anaesthesiologists that attempted neuraxial blockade before successful placement and total volume of local anaesthetic infused at delivery were recorded.

Side effects and complications as documented by either nursing staff or anaesthesiologist such as hypotension (> $20 \%$ drop in systolic blood pressure) and fetal bradycardia post-neuraxial blockade, inability to obtain cerebrospinal 
fluid (CSF) from the spinal needle inserted through the epidural needle in the CSE technique, venous puncture, inability to pass the epidural catheter through the epidural needle, paresthesia, dural puncture, symptoms of local anaesthetic toxicity, high blockade (sensory level of T1 and above), dislodgement of the epidural catheter, shivering, pruritus, nausea, vomiting and presence of breakthrough pain were also obtained from the electronic database.

Breakthrough pain was defined as a maternal complaint of pain that required the attending anaesthesiologist to administer an additional bolus of local anaesthetic agent. A common regimen would be $0.2-$ $0.3 \%$ ropivacaine $5-10 \mathrm{ml}$, with or without epidural opioids (fentanyl $50 \mathrm{mcg}$ ). The reason for inadequate pain relief (inadequate level, unilateral blockade, patchy block, perineal pain or back pain), cervical dilatation, oxytocin infusion rate $(\mathrm{ml} / \mathrm{hr})$, the volume and concentration of local anaesthetic agent administered and the pain scores before and after the additional administration of an epidural bolus were documented. Epidural catheter re-siting was defined as the need to remove the epidural catheter and perform another neuraxial block procedure. The decision to re-site the epidural catheter was at the discretion of the attending anaesthesiologist on duty and was recorded.

\section{Study outcome}

The study outcome was the incidence of epidural catheter re-siting in all parturients that received labour neuraxial analgesia (CSE or plain epidural analgesia) - this was treated as binary data with categories as "requiring epidural catheter re-siting" or "not requiring epidural catheter re-siting".

\section{Statistical analysis}

Logistic regression model was used to find the effect of each variable on epidural catheter re-siting. Variables available prior to the epidural catheter re-siting procedure assumed to be associated were maternal age (years), race, maternal weight $(\mathrm{kg})$, maternal height $(\mathrm{cm})$, maternal BMI $\left(\mathrm{kg} / \mathrm{m}^{2}\right)$, quantity of dinoprostone (prostin E2), cervical dilatation pre-neuraxial blockade $(\mathrm{cm})$, mode of delivery, spontaneous labour onset, labour onset: artificial rupture of membranes, labour onset: dinoprostone insertion, type of anaesthetic technique, number of anaesthetists, time taken for neuraxial block ( $\mathrm{min}$ ), post epidural pain score, total volume of local anaesthetic infused at delivery (ml), incidence of breakthrough pain, hypotension, shivering, inability to obtain CSF in the CSE technique, venous puncture and inability to pass catheter through epidural needle. Variables with $p$-value $<0.3$ on the univariate logistic regression analysis or that were clinically meaningful were included in the multivariable logistic regression model. Several clinical interactions were also considered. The union of the variables from forward, backward and stepwise variables selection methods were used to finalize the list of variables in the multivariable model with entry and stay criteria as 0.9 and 0.2 respectively. Improvement in model performance through the addition of new candidate variables in multivariable logistic regression models was tested using concordance statistics (C-Statistics) with Akaike information criterion (AIC). AIC measures both the accuracy and complexity of a model. For a given situation, a model with lower AIC generally has the better generalizability [10]. The logistic regression model develops a score which is a linear combination of selected variables. This score can be converted to the estimated probability of epidural catheter re-siting using the following formula:

Estimated probability $=\frac{\mathrm{e}^{\text {Score }}}{1+\mathrm{e}^{\text {Score }}}$, where e is natural exponential.

Sensitivity, specificity, positive predictive value and negative predictive value were also calculated. To obtain realistic and generalizable accuracy estimates, we first randomly split data from the 2014-2015 set with parturients that received labour neuraxial analgesia in our centre into two sets: 70 and 30\% parturients was referred as training data and internal validation data, respectively. The training data was used to finalize the predictive model. The predictive accuracy of the model based on the internal validation data was assessed using $\mathrm{C}$ - statistic. This model's predictive accuracy and robustness was further assessed again using the 2012-2013 data set on parturients that received labour neuraxial analgesia in our centre. Point and interval estimates of the C-Statistics were generated.

Parturients' demographic, obstetric and anaesthetic data were also summarized based on their status of epidural catheter re-siting: "requiring epidural catheter re-siting" or "not requiring epidural catheter re-siting". Continuous and categorical variables were summarized as frequency (percentage) or mean (standard deviation (SD)) respectively. Data was summarized for all available data sets: training, internal validation and external validation data. Association from logistic regression model was expressed as $\beta$ coefficient along with associated $95 \%$ confidence interval $(95 \% \mathrm{CI})$. We have also expressed this association in terms of odds ratio (OR). A $p$ - value $<0.05$ was considered as statistical significance for a two-sided test. Analysis was done using SAS version 9.3 software (SAS Institute Inc; Cary, NC, USA).

\section{Results}

From 1 January 2014 to 31 December 2015, 10,628 parturients received labour epidural analgesia at our centre. Ninety-three $(0.88 \%)$ parturients required re-siting of their epidural catheters. From January 2012 to December 2013, there were 10,170 parturients that received labour 
epidural analgesia and $86(0.85 \%)$ paturients required epidural catheter re-siting. (Fig. 1).

\section{Training and internal validation data}

The 2014-2015 data were randomly divided in training and internal validation data. Training data comprised of $7439(70 \%)$ parturients was used to develop predictive model while internal validation data comprised of 3189 (30\%) parturients to check the predictive property of the predictive model. There were 57 (0.77\%), 36 (1.13\%) and $86(0.85 \%)$ cases of epidural catheter re-siting in the training, internal validation and external validation data respectively. 6930 (93.2\%), 2958 (92.7\%) and 9533 (94.7\%) parturients received a CSE in the training, internal validation and external validation data respectively. Characteristics of the three data are shown in Table 1.

Univariate logistic regression analysis of the training data showed that cervical dilatation $(\mathrm{OR}(95 \% \mathrm{CI}): 0.69$ (0.51, 0.94)) (for each $\mathrm{cm}$ increase), incidence of break through pain (OR(95\%CI): 19.74 $(10.76,36.21))$, inability to obtain CSF in the CSE technique (OR(95\%CI): $6.19(2.43,15.78))$, post-epidural insertion pain score $(\mathrm{OR}(95 \% \mathrm{CI}): 1.38$ (1.19, 1.59)) (for every one unit increase) and venous puncture $(\mathrm{OR}(95 \% \mathrm{CI}): 3.85(1.63,9.06))$ were significantly associated with epidural catheter re-siting. Final multivariable predictive model after stepwise, forward and backward selection method included the following variables-incidence of break through pain $(\mathrm{OR}(95 \% \mathrm{CI}): 4.42(3.25,6.02))$, age of parturient (OR(95\%CI): 1.07 (1.01, 1.12)) (for each year),

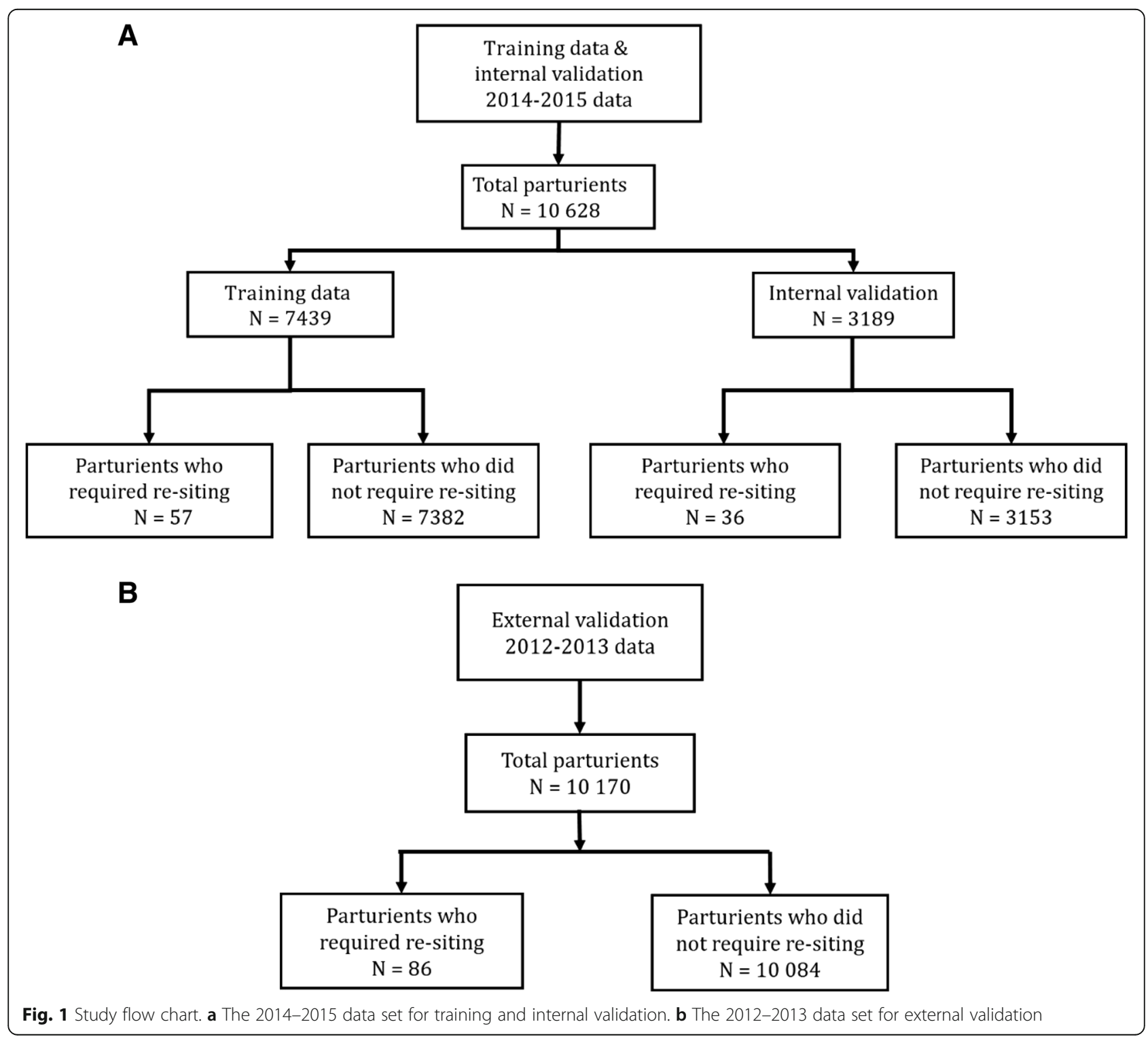


Table 1 Patient's demographic, clinical and anesthetic characteristics of patients in training, internal and external validation data

\begin{tabular}{|c|c|c|c|c|c|c|}
\hline \multirow[t]{3}{*}{ Characteristics } & \multirow{2}{*}{\multicolumn{2}{|c|}{$\begin{array}{l}\text { Training data } \\
(N=7439) \\
\text { Epidural re-siting }\end{array}$}} & \multirow{2}{*}{\multicolumn{2}{|c|}{$\begin{array}{l}\text { Internal validation data } \\
(N=3189) \\
\text { Epidural re-siting }\end{array}$}} & \multirow{2}{*}{\multicolumn{2}{|c|}{$\begin{array}{l}\text { External validation data } \\
(N=10,170) \\
\text { Epidural re-siting }\end{array}$}} \\
\hline & & & & & & \\
\hline & $\begin{array}{l}\text { No } \\
(N=7382)\end{array}$ & $\begin{array}{l}\text { Yes } \\
(N=57)\end{array}$ & $\begin{array}{l}\text { No } \\
(N=3153)\end{array}$ & $\begin{array}{l}\text { Yes } \\
(N=36)\end{array}$ & $\begin{array}{l}\text { No } \\
(\mathrm{N}=10,084)\end{array}$ & $\begin{array}{l}\text { Yes } \\
(N=86)\end{array}$ \\
\hline \multicolumn{7}{|l|}{ Demographic Data } \\
\hline Age (years), mean (SD) & $30.2(5.0)$ & $31.2(4.3)$ & $30.2(4.9)$ & $30.0(4.6)$ & $29.9(5.0)$ & $29.1(5.0)$ \\
\hline \multicolumn{7}{|l|}{ Race, n(\%) } \\
\hline Chinese & $3421(46.3)$ & $22(38.6)$ & $1488(47.2)$ & $11(30.6)$ & $4805(47.6)$ & $31(36.0)$ \\
\hline Indian & $956(13.0)$ & $9(15.8)$ & $407(12.9)$ & $8(22.2)$ & $1263(12.5)$ & $14(16.3)$ \\
\hline Malay & $1657(22.4)$ & $15(26.3)$ & $648(20.6)$ & $11(30.6)$ & $2361(23.4)$ & $19(22.1)$ \\
\hline Others & $1348(18.3)$ & $11(19.3)$ & $610(19.3)$ & $6(16.7)$ & $1655(16.4)$ & $22(25.6)$ \\
\hline Maternal weight (kg), mean (SD) & $68.2(13.1)$ & $70.7(12.1)$ & $68.0(12.9)$ & $69.2(12.4)$ & $69.2(13.0)$ & $71.8(14.3)$ \\
\hline Maternal height (cm), mean (SD) & $160(6)$ & $160(6)$ & $160(5)$ & $160(6)$ & $158.7(8.5)$ & $157.6(6.3)$ \\
\hline Maternal BMI $\left(\mathrm{kg} / \mathrm{m}^{2}\right)$, mean (SD) & $27.1(6.0)$ & $28.1(4.2)$ & $27.0(4.8)$ & $28.1(4.6)$ & $27.5(5.5)$ & $28.9(5.1)$ \\
\hline \multicolumn{7}{|l|}{ Obstetric Data } \\
\hline Quantity of dinoprostone, mean (SD) & $0.4(0.8)$ & $0.5(0.8)$ & $0.4(0.7)$ & $0.6(1.1)$ & $1.2(2.7)$ & $2.1(2.7)$ \\
\hline Cervical dilatation pre-neuraxial blockade (cm), mean (SD) & $3.5(1.0)$ & $3.2(0.8)$ & $3.5(1.0)$ & $3.0(0.8)$ & $3.5(1.2)$ & $3.1(0.9)$ \\
\hline \multicolumn{7}{|l|}{ Mode of delivery, n (\%) } \\
\hline Instrumental delivery & $738(10.0)$ & $2(3.5)$ & $293(9.3)$ & $8(22.2)$ & $1017(10.1)$ & $11(12.8)$ \\
\hline Caesarean Section & $1288(17.5)$ & $22(38.6)$ & $498(15.8)$ & $11(30.6)$ & $1675(16.7)$ & $29(33.7)$ \\
\hline Normal vaginal delivery & $5355(72.6)$ & $33(57.9)$ & $2362(74.9)$ & $17(47.2)$ & $7345(73.2)$ & $46(53.5)$ \\
\hline \multicolumn{7}{|l|}{ Spontaneous labour onset, n (\%) } \\
\hline No & $3532(47.8)$ & $31(54.4)$ & $1537(48.7)$ & $17(47.2)$ & $5293(52.5)$ & $46(53.5)$ \\
\hline Yes & $3850(52.2)$ & $26(45.6)$ & $1616(51.3)$ & $19(52.8)$ & $4791(47.5)$ & $40(46.5)$ \\
\hline \multicolumn{7}{|l|}{ Labour onset, artificial rupture of membranes, n(\%) } \\
\hline No & $5530(74.9)$ & $46(80.7)$ & $2348(74.5)$ & $31(86.1)$ & $7091(70.3)$ & $71(82.6)$ \\
\hline Yes & $1852(25.1)$ & $11(19.3)$ & $805(25.5)$ & $5(13.9)$ & $2993(29.7)$ & $15(17.4)$ \\
\hline \multicolumn{7}{|l|}{ Labour onset, dinoprostone insertion, n (\%) } \\
\hline No & $5435(73.6)$ & $37(64.9)$ & $2309(3.2)$ & $23(63.9)$ & $7133(70.7)$ & $49(57.0)$ \\
\hline Yes & $1947(26.4)$ & $20(35.1)$ & $844(26.8)$ & $13(36.1)$ & $2951(29.3)$ & $37(43.0)$ \\
\hline \multicolumn{7}{|l|}{ Anaesthetic Data } \\
\hline \multicolumn{7}{|l|}{ Type of anaesthetic technique, n (\%) } \\
\hline CSE & $6878(93.2)$ & $52(91.2)$ & $2929(92.9)$ & $29(80.6)$ & $9548(94.8)$ & $75(87.2)$ \\
\hline Epidural & $504(6.8)$ & $5(8.8)$ & $224(7.1)$ & $7(19.4)$ & $526(5.2)$ & $11(12.8)$ \\
\hline \multicolumn{7}{|l|}{ Number of anaesthetists, $\mathrm{n}(\%)$} \\
\hline 1 & $7228(97.9)$ & $56(98.2)$ & $3106(98.5)$ & $35(97.2)$ & $9923(98.5)$ & $84(97.7)$ \\
\hline 2 & $152(2.1)$ & $1(1.8)$ & $46(1.5)$ & $1(2.8)$ & $152(1.5)$ & $1(1.2)$ \\
\hline 3 & $2(0.0)$ & $0(0.0)$ & $1(0.0)$ & $0(0.0)$ & $3(0.0)$ & $1(1.2)$ \\
\hline Time taken for neuraxial block (min), mean (SD) & $7.9(5.9)$ & $8.2(6.0)$ & $7.6(5.2)$ & $10.4(7.8)$ & $6.9(4.8)$ & $9.2(7.2)$ \\
\hline Post epidural pain score, median (IQR) & $0.0(0.0)$ & $0.0(0.0)$ & $0(0.0)$ & $0.0(1.0)$ & $0.0(0.0)$ & $0.0(0.0)$ \\
\hline Total volume of local anaesthetic infused at delivery (ml), mean (SD) & $57.1(44.1)$ & $92.6(69.5)$ & $57.1(44.0)$ & $87.6(62.0)$ & $56.3(43.1)$ & $87.3(59.5)$ \\
\hline \multicolumn{7}{|l|}{ Incidence of breakthrough pain, n (\%) } \\
\hline Yes & $994(13.5)$ & $43(75.4)$ & $430(13.6)$ & $31(86.1)$ & $1386(13.7)$ & $68(79.1)$ \\
\hline No & $6388(86.5)$ & $14(24.6)$ & $2723(86.4)$ & $5(13.9)$ & $8698(86.3)$ & $18(20.9)$ \\
\hline
\end{tabular}


Table 1 Patient's demographic, clinical and anesthetic characteristics of patients in training, internal and external validation data (Continued)

\begin{tabular}{|c|c|c|c|c|c|c|}
\hline \multirow[t]{3}{*}{ Characteristics } & \multirow{2}{*}{\multicolumn{2}{|c|}{$\begin{array}{l}\text { Training data } \\
(N=7439) \\
\text { Epidural re-siting }\end{array}$}} & \multirow{2}{*}{\multicolumn{2}{|c|}{$\begin{array}{l}\text { Internal validation data } \\
(N=3189) \\
\text { Epidural re-siting }\end{array}$}} & \multirow{2}{*}{\multicolumn{2}{|c|}{$\begin{array}{l}\text { External validation data } \\
(N=10,170) \\
\text { Epidural re-siting }\end{array}$}} \\
\hline & & & & & & \\
\hline & $\begin{array}{l}\text { No } \\
(N=7382)\end{array}$ & $\begin{array}{l}\text { Yes } \\
(N=57)\end{array}$ & $\begin{array}{l}\text { No } \\
(N=3153)\end{array}$ & $\begin{array}{l}\text { Yes } \\
(N=36)\end{array}$ & $\begin{array}{l}\text { No } \\
(N=10,084)\end{array}$ & $\begin{array}{l}\text { Yes } \\
(N=86)\end{array}$ \\
\hline \multicolumn{7}{|c|}{ Hypotension, n (\%) } \\
\hline Yes & $50(0.7)$ & $0(0.0)$ & $16(0.5)$ & $0(0.0)$ & $77(0.8)$ & $4(4.7)$ \\
\hline No & $7332(99.3)$ & $57(100.0)$ & $3137(99.5)$ & $36(100.0)$ & $10,007(99.2)$ & $82(95.3)$ \\
\hline \multicolumn{7}{|c|}{ Shivering, n (\%) } \\
\hline Yes & $1681(22.8)$ & $13(22.8)$ & $676(21.4)$ & $8(22.2)$ & $2526(25.0)$ & $32(37.2)$ \\
\hline No & $5701(77.2)$ & $44(77.2)$ & $2477(78.6)$ & $28(77.8)$ & $7558(75)$ & $54(62.8)$ \\
\hline \multicolumn{7}{|c|}{ Inability to obtain CSF in the CSE technique, n (\%) } \\
\hline Yes & $113(1.5)$ & $5(8.8)$ & $48(1.5)$ & $5(13.9)$ & $169(1.7)$ & $7(8.1)$ \\
\hline No & $7269(98.5)$ & $52(91.2)$ & $3105(98.5)$ & $31(86.1)$ & 9915 (98.3) & $79(91.9)$ \\
\hline \multicolumn{7}{|c|}{ Venous puncture, n (\%) } \\
\hline Yes & $219(3.0)$ & $6(10.5)$ & $104(3.3)$ & $8(22.2)$ & $318(3.2)$ & $10(11.6)$ \\
\hline No & $7163(97.0)$ & $51(89.5)$ & $3049(96.7)$ & $28(77.8)$ & $9766(96.8)$ & $76(88.4)$ \\
\hline \multicolumn{7}{|c|}{ Inability to pass catheter through epidural needle, n(\%) } \\
\hline Yes & $26(0.4)$ & $1(1.8)$ & $9(0.3)$ & $0(0.0)$ & $5(0.0)$ & $2(2.3)$ \\
\hline No & $7356(99.6)$ & $56(98.2)$ & $3144(99.7)$ & $36(100.0)$ & $10,079(100.0)$ & $84(97.7)$ \\
\hline
\end{tabular}

BMI Body mass index, CSE Combined spinal epidural

artificial rupture of membranes $(\mathrm{OR}(95 \% \mathrm{CI})$ : 0.33 (0.1, 1.03)), dinoprostone (Prostin E2) use for induction of labour (OR(95\%CI): $0.38(0.12,1.18))$, spontaneous onset of labour $(\mathrm{OR}(95 \% \mathrm{CI})$ : $0.31(0.10,0.98))$, post-epidural insertion pain score $(\mathrm{OR}(95 \% \mathrm{CI}): 1.35(1.14,1.61))$ and problems such as inability to obtain CSF in the CSE technique
$(\mathrm{OR}(95 \% \mathrm{CI}): \quad 2.06 \quad(1.2, \quad 3.53))$, venous puncture (OR(95\%CI): $1.70(1.08,2.68))$ and inability to pass catheter through the epidural needle $(\mathrm{OR}(95 \% \mathrm{CI}): 1.93(0.65,5.74))$ (Table 2). C-Statistic $(95 \% \mathrm{CI})$ and AIC for this model was $0.89(0.86,0.93)$ and 545.381 respectively (Fig. 2). Predictive model for epidural catheter re-siting was as follows:

Table 2 Multivariate logistic regression analysis for epidural re-siting predictive risk factors based on internal training data

\begin{tabular}{|c|c|c|c|c|c|c|}
\hline \multirow[t]{2}{*}{ Risk factors } & \multirow[t]{2}{*}{$\beta$ coefficients } & \multirow{2}{*}{$\begin{array}{l}\text { Standard } \\
\text { error (SE) }\end{array}$} & \multirow[t]{2}{*}{$P$ - value } & \multirow{2}{*}{$\begin{array}{l}\text { Adjusted Odds } \\
\text { ratio (OR) }\end{array}$} & \multicolumn{2}{|c|}{$95 \%$ confidence interval of OR } \\
\hline & & & & & Lower & Upper \\
\hline Intercept & -5.9334 & 1.1434 & $<0.0001$ & & & \\
\hline Age & 0.0632 & 0.0271 & 0.0197 & 1.065 & 1.0102 & 1.1233 \\
\hline Post-epidural Pain Score & 0.3025 & 0.0881 & 0.0006 & 1.353 & 1.1388 & 1.6082 \\
\hline Breakthrough Pain $($ Ref = No) & 1.4866 & 0.1573 & $<0.0001$ & 4.422 & 3.2485 & 6.0189 \\
\hline Artificial rupture of membranes $(\operatorname{Ref}=\mathrm{No})$ & -1.1134 & 0.5831 & 0.0562 & 0.328 & 0.1047 & 1.0298 \\
\hline $\begin{array}{l}\text { Dinoprostone insertion for induction of } \\
\text { labour (Ref = No) }\end{array}$ & -0.9640 & 0.5775 & 0.0951 & 0.381 & 0.123 & 1.1828 \\
\hline Spontaneous onset of Labour $(\operatorname{Ref}=\mathrm{No})$ & -1.1744 & 0.5877 & 0.0457 & 0.309 & 0.0977 & 0.9777 \\
\hline $\begin{array}{l}\text { Inability to obtain CSF in the CSE technique } \\
(\text { Ref }=\text { No) }\end{array}$ & 0.7232 & 0.2746 & 0.0085 & 2.061 & 1.2032 & 3.5307 \\
\hline Venous puncture $(\operatorname{Ref}=\mathrm{No})$ & 0.5321 & 0.2322 & 0.0219 & 1.702 & 1.0802 & 2.6834 \\
\hline $\begin{array}{l}\text { Inability to pass catheter through epidural } \\
\text { needle (Ref }=\text { No) }\end{array}$ & 0.6551 & 0.5576 & 0.2400 & 1.925 & 0.6455 & 5.7431 \\
\hline
\end{tabular}




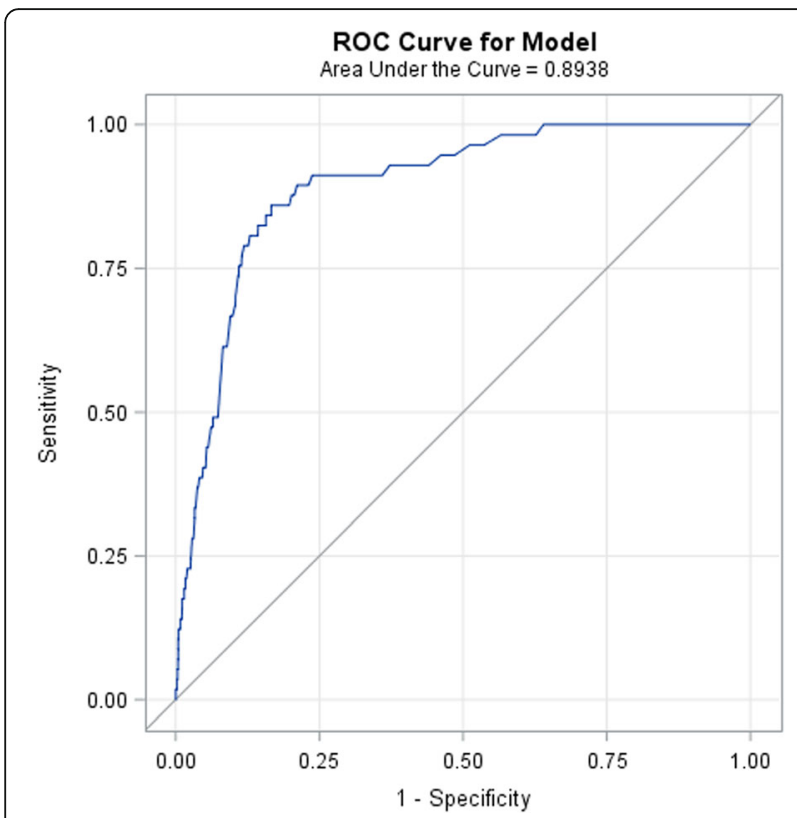

Fig. 2 ROC curve of the predictive model on the training data set. $\operatorname{AUC}(95 \% \mathrm{Cl})=0.89(0.86,0.93)$

$$
\begin{aligned}
\text { Score } & =-5.9334+(0.0632 * \text { Age }) \\
& +(0.3025 * \text { post-epidural insertion pain score }) \\
& +(1.4866 * \text { incidence of break through pain }) \\
& -(1.1134 * \text { labour onset artificial rupture of membranes }) \\
& -(0.9640 * \text { labour onset dinoprostone }(\text { ProstinE } 2)) \\
& -(1.1744 * \text { labour onset spontaneous }) \\
& +(0.7232 * \text { problem of unable to get CSF for CSE }) \\
& +(0.5321 * \text { problem of venous puncture }) \\
& +(0.6551 * \text { problem of unable to pass catheter })
\end{aligned}
$$

and estimated probability $=\frac{e^{\text {score }}}{1+\mathrm{e}^{\text {score }}}$.

Incidence of breakthrough pain and the parturients's age had significant roles in the predictive model. C-Statistic $(95 \% \mathrm{CI})$ and AIC droped to $0.66(0.58,0.73)$ and 650.76 , respectively after removing incidence of breakthrough pain from the final multivariate model. Similarly, the C-Statistic $(95 \% \mathrm{CI})$ and AIC were reduced to $0.86(0.82,0.92)$ and 548.79 respectively after removing parturients's age. As an example, for a 25 year-old mother who had CSF obtained from the spinal needle during the CSE insertion, experienced a venous puncture during the procedure, whose anaesthesiologist was unable to pass the catheter through the epidural needle, a post-epidural insertion pain score of 5 and who subsequently developed breakthrough pain-she would have score of 87.21 and would have a $70.52 \%$ probability of "requiring epidural catheter re-siting".

\section{Performance in internal and external validation data}

After fitting the above-mentioned predictive model, the internal validation data showed C-statistic $(95 \% \mathrm{CI})$ as
$0.92(0.88,0.97)$ (Fig. 3). Using a threshold for the probability of epidural catheter re-siting of 0.02 , the sensitivity and specificity to predict epidural catheter re-siting ranged from 0.73 to 0.96 and 0.85 to 0.87 respectively. Similarly, the C-statistic $(95 \% \mathrm{CI})$ for external validation data was 0.89 (0.86, 0.92) (Fig. 4). These estimates are very much consistent with the corresponding estimate based on the training data. Performance of model based on C - statistic using 2014-2015 and 2012-2013 data were also provided in Table 3.

\section{Discussion}

The incidence of epidural catheter re-siting in 2014-2015 in our centre was $0.88 \%$, which was similar to the incidence of $0.85 \%$ in 2012-2013 [4], and was lower than the reported incidence in other centres of about 1.6-6.8\% [11-13]. The similarity in the incidence of epidural catheter re-siting between the two time periods in our centre could be attributed to our standardized guidelines for managing inadequate epidural analgesia in labour.

\section{Predictive factors for epidural catheter re-siting}

Increasing age, the presence of breakthrough pain, higher pain scores immediately after post-epidural insertion, the inability to obtain CSF in the CSE technique and a venous puncture during the neuraxial blockade were found to be predictive of epidural re-siting, while the spontaneous onset of labour was found to be protective.

The presence of breakthrough pain was the most significant independent risk factor for epidural catheter

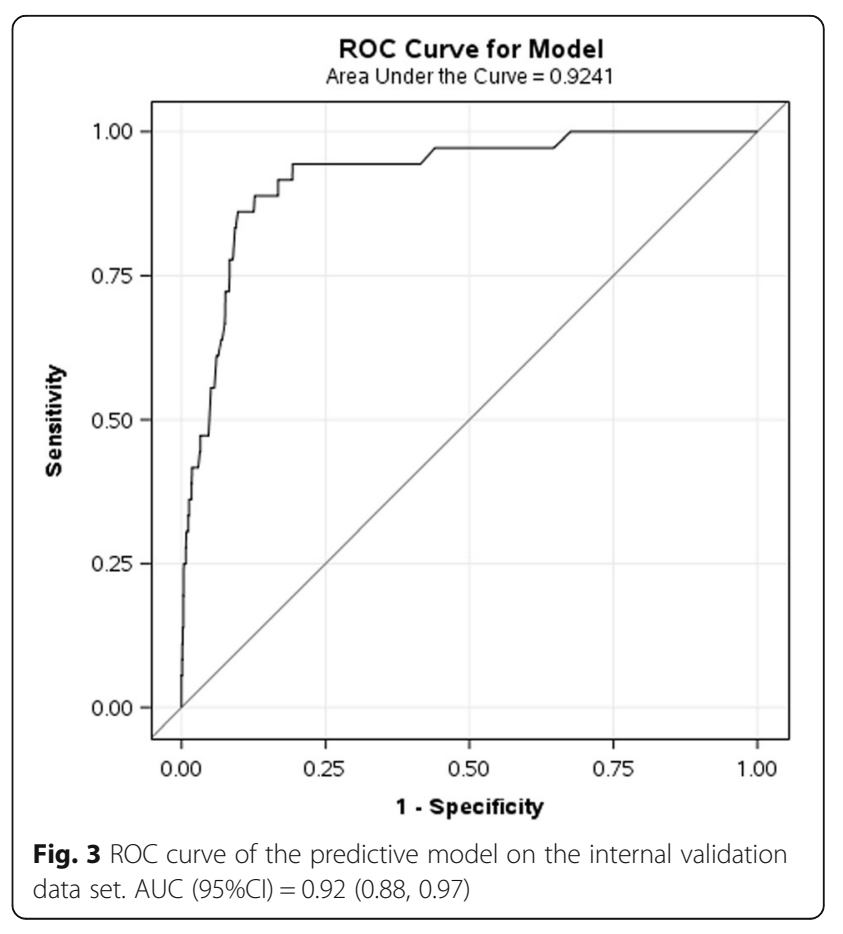




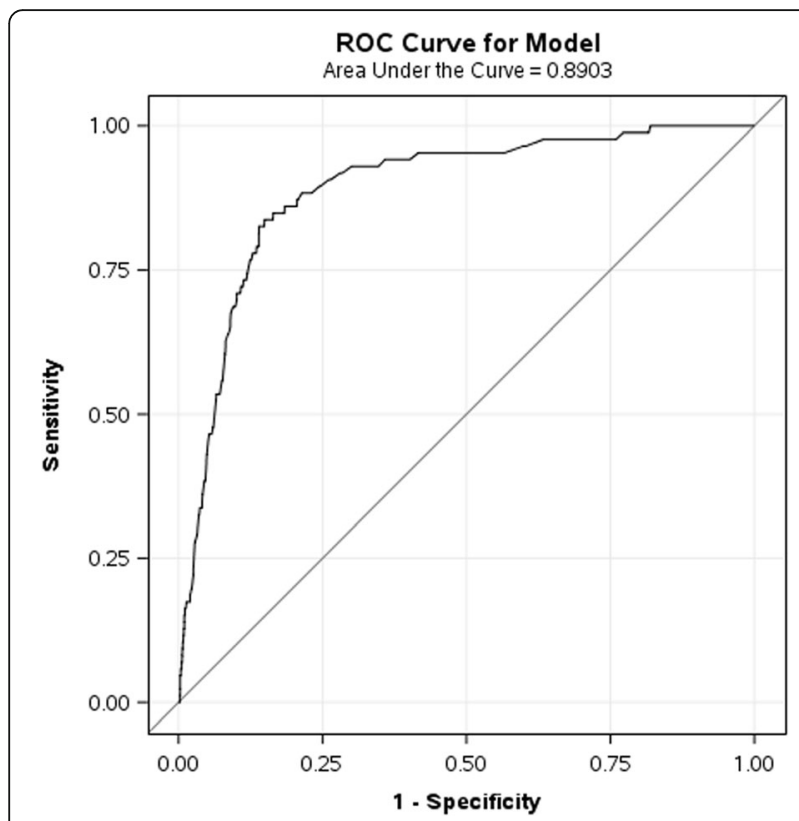

Fig. 4 ROC curve of the predictive model on the external validation data set. $\mathrm{AUC}(95 \% \mathrm{Cl})=0.89(0.86,0.92)$

re-siting (OR(95\%CI): $4.42(3.25,6.02))$. The incidence of breakthrough pain has been reported to range from 12 to $33 \%[5,11,14]$. However, the incidence of breakthrough pain was $14.1 \%$ in this study, which was similar to the incidence of $14.3 \%$ from our previous results [4]. Breakthrough pain has been shown to be associated with multiple factors such as maternal characteristics, obstetric or anaesthetic factors, including an increased body mass index, dysfunctional labour [15] and catheter related issues [16] associated with inadequate analgesia.

The majority of breakthrough pain is managed conservatively with an additional bolus of local anaesthetic with or without fentanyl via the epidural catheter [17]. However, if labour is prolonged, it may be appropriate to re-site the epidural catheter to minimize maternal distress and to reestablish adequate pain relief. Moreover, should a Caesarean section be subsequently required, the sensory blockade can be extended to achieve reliable anaesthesia for surgery. Recurrent breakthrough pain during labour epidural analgesia has been shown to be a predictive factor for failed augmentation for anaesthesia for Caesarean section [18].

In our centre, $93.0 \%$ of the labour epidural analgesia administered was using the CSE technique. The onset of

Table 3 Performance of predictive models based on training, internal and external validation data

\begin{tabular}{|c|c|c|c|}
\hline \multirow[t]{2}{*}{ Measures } & \multicolumn{2}{|l|}{$2014-2015$} & \multirow{2}{*}{$\begin{array}{l}\text { 2012-2013 } \\
\text { External validation }\end{array}$} \\
\hline & Training data & Internal validation & \\
\hline $\begin{array}{l}\mathrm{C}- \\
\text { statistic }\end{array}$ & $0.894(0.858,0.930)$ & $0.924(0.882,0.966)$ & $0.890(0.858,0.923)$ \\
\hline
\end{tabular}

pain relief has been shown to be more rapid and more reliable using the CSE technique than plain epidural analgesia alone, and is also less likely associated with recurrent breakthrough pain $[8,19]$. A higher pain score immediately after post-neuraxial blockade (OR $(95 \% \mathrm{CI})$ : $1.35(1.14,1.61))$ could possibly indicate a failure of the CSE technique and the parturient may subsequently then require epidural catheter re-siting. Groden et al. found that the CSE technique is less likely to fail during labour and that the time to detection of a failed catheter was significantly longer compared to epidural only technique, which also gives evidence that CSE is a more reliable technique [20].

Increasing age is associated with increased difficulty of neuraxial blockade [21], which could be due to the calcification of ligaments of the spine and osteophyte formation. This could potentially result in an increased failure rate and increased need for epidural catheter re-siting. Although most parturients are expected to be young, maternal age is increasing. In our cohort, the wide age range of parturients (14 to 48 years) may account for increasing age being an independent predictive factor of epidural catheter re-siting. However, age was not found to be a factor influencing epidural re-siting in another observational study of epidural re-siting in labour analgesia [22].

Labour onset can be spontaneous or facilitated by the insertion of dinoprostone (Prostin E2) or the artificial rupture of membranes [23]. The spontaneous onset of labour (OR(95\%CI): $0.31(0.1,0.98))$ was identified to be an independent protective factor for epidural catheter re-siting. However, these are not mutually exclusive-a parturient may have spontaneous onset of labour and yet also had her membranes ruptured artificially. Nonetheless, these factors were included in the multivariate predictive model for epidural catheter re-siting.

Technical problems during the procedure have also been identified to be independent risk factors for epidural catheter re-siting. During a CSE insertion, after the epidural space has been identified with a loss of resistance, insertion of the spinal needle through the back-eye of the epidural needle may not attain a dural puncture to administer the spinal component. Because the dural sac is triangular-shaped at the lumbar level with the base directed anteriorly, if the epidural needle is not placed in the midline, the spinal needle would not puncture the dura if placed off midline [24]. A plain epidural technique may be performed instead and the CSE procedure abandoned to minimize distress from another neuraxial attempt. However, an epidural catheter that is inserted in conjunction with a CSE technique has a greater likelihood of being in the correct space and providing adequate pain relief [25]. Our findings are consistent with another study that found that CSEs were less likely to be re-sited compared to a plain epidural technique for 
labour analgesia [22]. Thus, the inability to obtain CSF during the CSE technique is a predictive risk factor of epidural catheter re-siting-this could be associated with inadequate pain relief. At our centre, the landmark technique is the predominant method used during epidural catheter insertion; there is recent evidence that ultrasound guidance could reduce the rate of epidural resiting and decrease the number of attempts by junior residents [26].

Venous puncture during neuraxial blockade placement is predictive for epidural catheter re-siting. Intravenous placement of the epidural catheter can occur in 5-7\% [11] of labour epidurals and is more common in parturients because of a distended venous plexus from compression of the gravid uterus [27]. Venous placement of the epidural catheter may later present as a non-working labour epidural or systemic toxicity [27]. The methods that could reduce the risk of venous puncture include positioning the patient in a lateral position as opposed to sitting during epidural catheter placement, administration of fluid through the epidural needle before threading the epidural catheter into the space and using single-orifice catheters [28].

\section{Strengths of study}

Epidural catheter re-siting in parturients can be distressing and has also been found to be associated with maternal dissatisfaction [29]. The robustness of our predictive model (C-statistic of $0.89,0.92$ and 0.89 when used on the training, internal validation and respectively) enables the anaesthesiologist to reliably identify and target modifiable risk factors that predict epidural catheter re-siting. This could potentially decrease the likelihood of epidural catheter re-siting, thereby improving maternal satisfaction. Moreover, the early identification of such parturients so that a higher epidural catheter re-siting risk can be communicated among the clinicians in a timely manner.

Another strength of the study is the large number of patients that were included in the cohort, which is advantageous for the uncommon outcome of epidural catheter re-siting. We also externally validated the multivariate model with the predictive factors for epidural catheter re-siting with our previous 2012-2013 data, which increased the robustness of the model and the validity of the results. To our knowledge, there have been no other large scale studies that have developed such a predictive model.

\section{Limitations of study}

The limitations of this retrospective cohort study could be related to selection bias and confounding factors. A prospective cohort study, although ideal, will be logistically challenging because of the high patient workload of about 5000 labour epidural analgesia every year at our centre [4]. Although a standardised neuraxial labour analgesia form was used, there was still a small number of missing data in some variables [4]. These were excluded from analysis and the data was cross-checked if the values were extreme outliers. Labour epidural analgesia was also performed by multiple anaesthesiologists and charting was also performed by different midwives, who may differ in their reporting. However, guidelines on managing labour epidural analgesia at our centre remained unchanged in the two periods which was a continuum. The anesthesiologists were different in the two time periods because anaesthesiology residents rotated through our centre for training. Nonetheless, this was not found to be a predictive risk factor for epidural catheter re-siting.

Our previous study identified independent risk factors that were associated with epidural catheter re-siting. The associated factors included both variables obtained prior and post to the epidural catheter re-siting procedure. In this study, we only chose those variables available prior to the epidural catheter re-siting procedure with $p$-value $<0.3$ on the univariate analysis or that were clinically meaningful to develop the predictive model for epidural catheter re-siting. The exclusion of factors that occurred after epidural catheter re-siting (e.g. need for Caesarean section for delivery etc.) may have possibly changed the weightage of the other factors in this predictive model, thus accounting for the differences seen in the factors identified between the current and previous study.

\section{Conclusion}

In summary, we have developed and validated a predictive model for epidural catheter re-siting for labour analgesia. The knowledge of such factors helps identify parturients at high risk of epidural catheter re-siting early, thereby allowing timely targeted management. The predictive model could be further externally validated and refined with recent data from our electronic labour neuraxial analgesia database to improve its robustness.

\section{Abbreviations \\ AIC: Akaike information criteria; AUC: Area under curve; CSE: Combined spinal-epidural; CSF: Cerebrospinal fluid; OR: Odds ratio; ROC: Receiver operator characteristic; SD: Standard deviation}

\section{Acknowledgements}

We would like to thank Ms. Agnes Teo and Ms. Liu Juan (Clinical Research Coordinator, Department of Women's Anaesthesia, KK Women's and Children's Hospital, Singapore) for their administrative support.

\section{Funding}

The support for this study is through the National Medical Research Council (NMRC) Clinical Trials Grant (CTG13feb013) and the NMRC Centre Grant (CGAug16M003). 


\section{Availability of data and materials}

The datasets generated and analysed for this manuscript are not publicly available, but could be obtained from the corresponding author on reasonable request.

\section{Authors' contributions}

LJSE data collection, data analysis, drafted the manuscript and revised the manuscript. RS data analysis, drafted the manuscript and revised manuscript. $\mathrm{NLRH}$ data analysis and revised the manuscript. ATHS study design, data analysis and revised the manuscript. BLS study design, data analysis, revised the article and final approval of the version to be submitted. All authors read and approved the final manuscript.

\section{Ethics approval and consent to participate}

This study received approval by the Singhealth Centralised Institutional Review Board (CIRB) (Ref: 2017/2023) on 31 January 2017 and (Ref: 2012/259/D) on 12 April 2012.

\section{Consent for publication}

Not applicable.

\section{Competing interests}

The authors declare that they have no competing interests.

\section{Publisher's Note}

Springer Nature remains neutral with regard to jurisdictional claims in published maps and institutional affiliations.

\section{Author details}

'Department of Women's Anaesthesia, KK Women's and Children's Hospital, 100 Bukit Timah Road, Singapore 229899, Singapore. ${ }^{2}$ Centre for Quantitative Medicine, Duke-NUS Medical School, 8 College Road, Singapore 169857, Singapore. ${ }^{3}$ Division of Clinical Support Services, KK Women's and Children's Hospital, 100 Bukit Timah Road, Singapore 229899, Singapore.

${ }^{4}$ Anaesthesiology and Perioperative Sciences Academic Clinical Program, Duke-NUS Medical School, 8 College Road, Singapore, Singapore.

Received: 9 August 2018 Accepted: 12 November 2018

Published online: 29 November 2018

\section{References}

1. Jones L, Othman M, Dowswell T, Alfirevic Z, Gates S, Newburn M, et al. Pain management for women in labour: an overview of systematic reviews. Cochrane Database Syst Rev. 2012;3:CD009234.

2. Weibel $\mathrm{S}$, Jelting $\mathrm{Y}$, Afshari A, Pace NL, Eberhart LH, Jokinen J, et al. Patientcontrolled analgesia with remifentanil versus alternative parenteral methods for pain management in labour. Cochrane Database Syst Rev. 2017:4: CD011989.

3. Patel NP, El-Wahab N, Fernando R, Wilson S, Robson SC, Columb MO, et al. Fetal effects of combined spinal-epidural vs epidural labour analgesia: a prospective, randomised double-blind study. Anaesthesia. 2014;69(5):458-67.

4. Sng BL, Tan M, Yeoh CJ, Han NLR, Sultana R, Assam PN, et al. Incidence and risk factors for epidural re-siting in parturients with breakthrough pain during labour epidural analgesia: a cohort study. Int J Obstet Anesth. 2018; 34:28-36.

5. Agaram R, Douglas MJ, McTaggart RA, Gunka V. Inadequate pain relief with labor epidurals: a multivariate analysis of associated factors. Int J Obstet Anesth. 2009:18(1):10-4.

6. Le Coq G, Ducot B, Benhamou D. Risk factors of inadequate pain relief during epidural analgesia for labour and delivery. Can J Anaesth. 1998;45(8): 719-23.

7. Jocelyn O, Dinoo K, Samuel L, Leong SB. Strategies to reduce neuraxia failure during labour. Trends in Anaesthesia \& Critical Care. 2016;7-8(June 2016):41-6.

8. Hess PE, Pratt SD, Lucas TP, Miller CG, Corbett T, Oriol N, et al. Predictors of breakthrough pain during labor epidural analgesia. Anesth Analg. 2001; 93(2):414-8 4th contents page.

9. American Society of Anaesthesiologists: ASA Physical Status Classification System. https://www.asahq.org/standards-and-guidelines/asa-physical-statusclassification-system. Accessed 14 Oct 2018.
10. Nongpiur ME, Haaland BA, Perera SA, Friedman DS, He M, Sakata LM, et al Development of a score and probability estimate for detecting angle closure based on anterior segment coherence tomography. Am J Ophthalmol. 2014;157(1):32-8 e1.

11. Pan PH, Bogard TD, Owen MD. Incidence and characteristics of failures in obstetric neuraxial analgesia and anesthesia: a retrospective analysis of 19,259 deliveries. Int J Obstet Anesth. 2004;13(4):227-33.

12. Paech MJ, Godkin R, Webster S. Complications of obstetric epidural analgesia and anaesthesia: a prospective analysis of 10,995 cases. Int $J$ Obstet Anesth. 1998;7(1):5-11.

13. Hamilton $\mathrm{CL}$, Riley ET, Cohen SE. Changes in the position of epidural catheters associated with patient movement. Anesthesiology. 1997;86(4): 778-84 discussion 29A.

14. Sng BL, Zeng $Y$, de Souza NNA, Leong WL, Oh TT, Siddiqui FJ, et al. Automated mandatory bolus versus basal infusion for maintenance of epidural analgesia in labour. Cochrane Database Syst Rev. 2018;5:CD011344.

15. Sng BL, Zhang Q, Leong WL, Ocampo C, Assam PN, Sia AT. Incidence and characteristics of breakthrough pain in parturients using computerintegrated patient-controlled epidural analgesia. J Clin Anesth. 2015;27(4): 277-84

16. Motamed C, Farhat F, Rémérand F, Stéphanazzi J, Laplanche A, Jayr C. An analysis of postoperative epidural analgesia failure by computed tomography epidurography. Anesth Analg. 2006;103(4):1026-32.

17. Beilin Y, Zahn J, Bernstein HH, Zucker-Pinchoff B, Zenzen WJ, Andres LA. Treatment of incomplete analgesia after placement of an epidural catheter and administration of local anesthetic for women in labor. Anesthesiology. 1998;88(6):1502-6.

18. Lee S, Lew E, Lim Y, Sia AT. Failure of augmentation of labor epidural analgesia for intrapartum caesarean delivery: a retrospective review. Anesth Analg. 2009;108(1):252-4.

19. Collis RE, Davies DW, Aveling W. Randomised comparison of combined spinal-epidural and standard epidural analgesia in labour. Lancet. 1995; 345(8962):1413-6.

20. Groden J, Gonzalez-Fiol A, Aaronson J, Sachs A, Smiley R. Catheter failure rates and time course with epidural versus combined spinal-epidural analgesia in labour. Int J Obstet Anesth. 2016;26:4-7.

21. Ružman T, Gulam D, Haršanji Drenjančević I, Venžera-Azenić D, Ružman N, Burazin J. Factors associated with difficult neuraxial blockade. Local Reg Anesth. 2014;7:47-52.

22. Odor P. Logistic regression and analysis of epidural re-sites in 4056 pateintsan obstetric Anaesthesia database study. Poster present at: $34^{\text {th }}$ annual ESRA congress 2015; Ljubljana, Slovenia.

23. Mozurkewich EL, Chilimigras JL, Berman DR, Perni UC, Romero VC, King VJ, et al. Methods of induction of labour: a systematic review. BMC Pregnancy Childbirth. 2011;11:84.

24. Cook TM. Combined spinal-epidural techniques. Anaesthesia. 2000;55(1):42-64

25. Norris MC. Are combined spinal-epidural catheters reliable? Int J Obstet Anesth. 2000:9(1):3-6.

26. Vallejo MC, Phelps AL, Singh S, Orebaugh SL, Sah N. Ultrasound decreases the failed labor epidural rate in resident trainees. Int J Obstet Anesth. 2010; 19(4):373-8.

27. Arendt K, Segal S. Why epidurals do not always work. Rev Obstet Gynecol. 2008;1(2):49-55.

28. Mhyre JM, Greenfield ML, Tsen LC, Polley LS. A systematic review of randomized controlled trials that evaluate strategies to avoid epidural vein cannulation during obstetric epidural catheter placement. Anesth Analg. 2009:108(4):1232-42.

29. Tan DJA, Sultana R, Han NLR, Sia ATH, Sng BL. Investigating determinants for patient satisfaction in women receiving epidural analgesia for labour pain: a retrospective cohort study. BMC Anaesthesiol. 2018;18(1):50. 